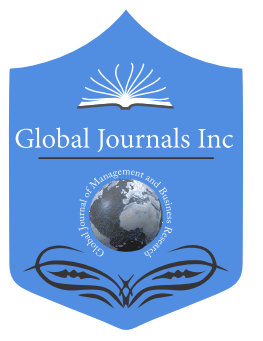

\title{
Critical Factors for the Development of Women Entrepreneurship in Retail Business of Bangladesh
}

\author{
By Dr. Nazrul Islam, Mohitul Ameen Ahmed Mustafi, Abid Aziz, \\ Amitava Bose Bapi, Dr. Sharmina Afrin \& Md. Monowar Uddin Talukdar \\ Khwaja Yunus Ali University
} Abstract- Development of women entrepreneurship in the SME sector has a crucial importance in a developing country like Bangladesh where women constitute half of the total population. The majority of them are underprivileged, under nourished, illiterate and poor. Hence, the development of women entrepreneurship has tremendous potentials for transforming the society through socioeconomic empowerment of the women. This potential is remained untapped in Bangladesh because of lower number of women entrepreneurs in business and economic activities. According to the Bangladesh Economic Review 2009, around six percent of the country's $\$ 90$ billion economy comes from SMEs, which is also the largest sector in terms of employment generation. But the women entrepreneurs are less than ten percent of the total entrepreneurs of the country. However, in the recent years, women entrepreneurship in small retail businesses of the country has been increasing which is a good sign for the positive growth of the economy.

Keywords: regulative factors, normative factors, cognitive factors, retail business, entrepreneurship, socioeconomic empowerment.

GJMBR-A Classification: JEL Code: L26

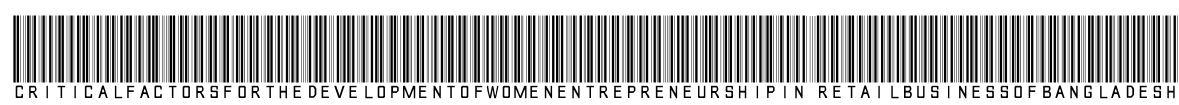

Strictly as per the compliance and regulations of:

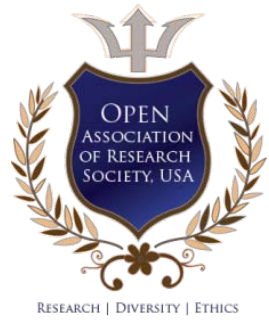

(C) 2021. Dr. Nazrul Islam, Mohitul Ameen Ahmed Mustafi, Abid Aziz, Amitava Bose Bapi, Dr. Sharmina Afrin \& Md. Monowar Uddin Talukdar. This research/review article is distributed under the terms of the Attribution-NonCommercial-NoDerivatives 4.0 International (CC BY-NC-ND 4.0). You must give appropriate credit to authors and reference this article if parts of the article are reproduced in any manner. Applicable licensing terms are at https://creativecommons.org/licenses/by-nc-nd/4.0/. 


\title{
Critical Factors for the Development of Women Entrepreneurship in Retail Business of Bangladesh
}

\author{
Dr. Nazrul Islam ${ }^{\alpha}$, Mohitul Ameen Ahmed Mustafi $^{\circ}$, Abid Aziz $^{\circ}$, Amitava Bose Bapi $^{\omega}$, Dr. Sharmina Afrin ${ }^{*}$ \\ \& Md. Monowar Uddin Talukdar ${ }^{\S}$
}

\begin{abstract}
Development of women entrepreneurship in the SME sector has a crucial importance in a developing country like Bangladesh where women constitute half of the total population. The majority of them are underprivileged, under nourished, illiterate and poor. Hence, the development of women entrepreneurship has tremendous potentials for transforming the society through socioeconomic empowerment of the women. This potential is remained untapped in Bangladesh because of lower number of women entrepreneurs in business and economic activities. According to the Bangladesh Economic Review 2009, around six percent of the country's $\$ 90$ billion economy comes from SMEs, which is also the largest sector in terms of employment generation. But the women entrepreneurs are less than ten percent of the total entrepreneurs of the country. However, in the recent years, women entrepreneurship in small retail businesses of the country has been increasing which is a good sign for the positive growth of the economy. Therefore, for the development of women entrepreneurship in retail business sector of Bangladesh, identification of critical factors is highly important. These factors can be classified into three types such as, regulative, normative, and cognitive factors. This paper aims at identifying the critical factors related to the development of women entrepreneurship in the retail business sector of Bangladesh. For identifying the factors, 218 women entrepreneurs of retail businesses were interviewed with a structured questionnaire. Both descriptive and inferential statistics were used in this study. Structural Equation Modeling (SEM) was used to identify the relationships between the critical factors and the overall development of women entrepreneurship in the retail business of Bangladesh. The results show that for the development of retail business women entrepreneurs, regulative, normative and cognitive factors are important. Regulative factors such as rules and regulations of the Government and its implementation are critical significant factors for the development of retail business women entrepreneurs in Bangladesh. This study suggests that
\end{abstract}

Author a: Pro-Vice Chancellor, Northern University Bangladesh (NUB), Dhaka, Bangladesh.e-mail: nazrulku@gmail.com

Author o: Department of Business Administration, School of Business, Khwaja Yunus Ali University, Bangladesh.

e-mail:mustafi559@gmail.com

Author $\rho$ w: School of Business, Uttara University, Bangladesh. e-mails: fmac911@hotmail.com, amitav.bapi@gmail.com

Author $¥$ : School of Business, Bangladesh University of Business \& Technology, Dhaka, Bangladesh. e-mail: sharmina1970@gmail.com

Author §: Department of Business Administration, School of Business Khwaja Yunus Ali University, Bangladesh.

e-mail:monowar.dba@kyau.edu.bd the government and the policy making organizations should come forward to overcome of normative and cognitive barriers of the women entrepreneurship in the retail business of Bangladesh.

Keywords: regulative factors, normative factors, cognitive factors, retail business, entrepreneurship, socioeconomic empowerment.

\section{BACKGROUND}

W omen entrepreneurship is very critical for any economy of the world. Women can contribute much more than men if they are provided with supports and equal resources. Food and Agricultural Organization (FAO) of the UN calculated that if women farmers, which is $43 \%$ of the agricultural labor force, in developing countries had the same access as men, agricultural output in 34 developing countries would rise by an expected average of up to $4 \%$, which could reduce the number of undernourished people in those countries by as much as $17 \%$, reducing approximately 150 million hungry people of the world. Women entrepreneurs possess many innate traits that can put them ahead in running a business successfully. Some of the traits are aptitude for learning, towering integrity, innate ability to build relationship, superb sense of ownership, higher adaptability, and knack for Human Resource Management. But women still are a minority of all entrepreneurs and face gender based discrimination to start, run and grow a business. Hence, women entrepreneurship can enhance women empowerment, improve economic wellbeing of the family and society and alienate poverty.

Bangladesh as a developing country of the world, women participation in business is a must for the emancipation of the economic status of the country. Although, Bangladesh has improved significantly in its economic order, educational development, social changes, and living standards, women entrepreneurs are not developed like men entrepreneurs. However, in recent years, a noticeable advancement is observed in women's increased participation in job and small entrepreneurial; businesses. Women bravely are overcoming the challenges posed by social systems to venture into small entrepreneurship, both in the urban and rural areas. The business activities differ but the 
performance is commendable against the social and cultural restrictions for women in Bangladesh, including the tremendous odds surrounding the socioeconomic order.

Study shows that most of the women entrepreneurs in Bangladesh do not have proper knowledge of establishing a start up and running a business (Habibullah, 1987). It also found that training can play an important role for women entrepreneurship development in Bangladesh. Finance is one of the most critical and important factor for starting a business in Bangladesh where women are lag behind. Bank is an important source of capital where women have limited access. But many of the entrepreneurs does not know how to write a project proposal to a bank for loan and how a bank evaluates the proposal before taking a decision to lend money (Habibur Rahman 1995). Aktaruddin (1999) found that the personal attributes are the key factors for entrepreneurial success or failure. Women entrepreneurs are mainly challenged by lack of funds, marketing deficits and discriminating treatment from supportive service agencies and government (Saleh 1995). Despite various initiatives, challenges of inadequate capital, sales promotion, permission for starting a business, gender discrimination, illiteracy, lack of business knowledge, non-availability of training programs, technical supports and lack of managerial experience are still prevailing against the women entrepreneurs which act as glass ceiling barriers for them. Therefore, this study tries to identify the critical factors for the development of women entrepreneurship in retail business of Bangladesh.

\section{il. Literature Review}

Women involvement in retail business of Bangladesh is remarkably increased in recent days. However, they face numerous challenges to work in a male-dominated society like Bangladesh with a competitive and highly complex economic and business environment. These problems often come from the society's culture and the local syndicates where females are perceived incapable to do independent job. Study show that inadequate capital, sales promotion, getting permission to start-up a business, gender discrimination, illiteracy, lack of knowledge, nonavailability of training program, barriers to access to technical support, lack of managerial experience, making ill talk by young people in some cases are the significant hindrances for women entrepreneurship development and so on. However, personal qualities such as hard work and perseverance, management and marketing skills, support provided by their spouses or family are the main reasons behind the success of the women entrepreneurs (Afroze, et.al., 2015). To establish a business, the initial problems faced by the female entrepreneurs seem similar to those confronted by female in other developing countries. However, the findings shows lower levels of work-family conflicts among Bangladeshi female entrepreneurs seem to differ with other countries in terms of their reasons for starting a business and succeeding in the venture (Rahmatullah \& Zaman, 2014). Study also identified that these challenges are faced by women borrowers other countries too. In Eldoret Town of Kenya, acquisition of credit from Women Enterprise fund are hindered by: long procedures involved in application and long processing, delay in loan disbursement, requirement that a member must have accumulated savings, lack of security/ collateral, requirement that one must be a member of a group first, and high cost of acquiring loan (Gedion, et. al., 2015). The study revealed inadequate funding and finance and the inability to clarify business goals as the main barriers restricting the success of the business for female entrepreneurs in South Africa (Meyer \& Mostert. 2016). Different internal and external factors affect the motivation, create obstacles to success and performance of firms created by women. It is clear that type of financial support, demographic factors, age at which the new business venture is undertaken, use of family loans and the initial size of firm are all instrumental in subsequent business success (Akehurst, et. al., 2012). To overcome these problems, government and family supports are crucial for the women entrepreneurs in developing countries like Bangladesh. Hence, the emergence and development of entrepreneurship largely depends on the supporting conditions of different factors such as economic, social, cultural, and psychological. Based on institutional theory, these factors can also be divided into regulative, normative and cognitive factors. Regulative factors refer to the rules and regulations of Government and other institutions that influence women entrepreneurship development in rural Bangladesh (Nawaz, 2009). Widespread illiteracy, lack of basic education, training and experience also remain serious obstacles in rural women's entrepreneurship development. Besides these, lack of awareness, social superstitious and the absence of rule of law also affect the rural women's participation in economic activities outside their family (Nawaz, 2009).

The creation of a new venture is a complex process that includes the actions, activities, thoughts, and processes. Some researchers conceptualized new venture creation as a process based on the effortperformance- outcome model where the effort is expended to start a business (performance) leads to certain desired outcomes (Kariv, D. (2013). Study also found that the external factors are more dominant than the internal ones in contributing to the business success of the One-District-One-Industry program (ODOI) entrepreneurs in Malaysia. The findings indicate that the government should actively play its pivotal role in (i) skill training since most rural businesses are labor intensive which involve skills and creativity; (ii) strengthening 
business competencies through more rigorous training; (iii) investment in infrastructure and facilities for a conducive local business environment; and (iv) effective market support services in terms of product promotion, market accessibility and networking (Kader, et. al., 2009). As long as success is concerned, the most significant factors affecting business success of SMEs in Bangladesh are concerned with the way of doing business, management know-how and, external environment (Philip, M. 2011). Study also identified more findings in this regard such as, (i) SMEs are of overwhelming importance in the region, as they account, on average per country, for more than 95\% of all firms in all sectors, (ii) the representation of women entrepreneurs is still relatively low which can be attributed to factors such as low level of education, lack of capital, and cultural or religious constraints, and (iii) most of women entrepreneurs in SMEs are from the category of "forced" entrepreneurs seeking for better family incomes (Tambunan, T. 2009). The concentration of women in low capital intensive industries which require less funding and at the same time have a lower potential for growth and development might also be driven by barriers against women regarding access to finance (Klapper \& Parker 2010). The study on microentrepreneurs in Pakistan, in this regard, reveals that at the time of entering into the venture, women are driven mainly by the pecuniary motives. They perceive customer service and relative business experience as the key success factors. Lack of access to financial capital, bureaucratic hurdles, and environmental uncertainty are the major barricades (Hussain \& Yaqub, 2010). The study conducted in Ethiopia on SME women entrepreneurs also identified problems in the areas of securing finances for establishing and running SMEs, lack of entrepreneurial and management competence and exposure, problems in finding the markets and distribution networks; limited opportunities for promotion and participation; limited amount of government and institutional support; absence of technological know-how and integration mechanism; and rampant corruption in an undisguised or disguised form, as major bottlenecks (Singh \& Belwal, 2008).

The women entrepreneurs are engaged in small business in different countries. Women Entrepreneurship Development (WED) Study in Africa showed that many women are still operating smaller businesses and doing so in localized markets and in feminized sectors. These businesses are under severe market pressure from competition both locally and internationally. These women entrepreneurs suffer to varying degrees from significant material constraints through to unhelpful attitudes arising from society's negative attitudes to women in business. Nearly all of the women interviewed have severe pressures on their time because of juggling business, household and community duties (Richardson, et. al., 2004). Study also identified that the female-owned businesses do have higher failure rates compared to male-owned businesses, the difference is not significant after controlling for the effects of industry (Watson, 2003).

In case of micro credit, total amount of microcredit financing, education, government support and experience are found significant for the rural women (Mohamad-Azahari, \& Joni-Tamkin, 2013). A survey was used to collect data from 224 Emirati female entrepreneurs. It was found that family is an important factor. Family support and contribution of family members to the business are important for business success (Jabeen, et. al., 2015). The specific obstacles and challenges faced by women are the lack of role models in entrepreneurship, Lack of experience, Lack of wealth, competing demands on time (Jahan, 2017).

Therefore, the core issues were identified by the women entrepreneurs like marketing, capacity building and training, access to finance, design and product development, regulatory barriers regarding tax, VAT and company registration, promotional activities, ICT etc. but in maximum cases women were deprived of due to negative attitude of our society \& community (Rahman, 2010). The factors taken into account in this study are summed up in Table 1.

Table 1: Independent Variables Concerning Retail Business Women Entrepreneurs

\begin{tabular}{|c|c|c|}
\hline Factor Name & Items & Authors Name \\
\hline \multirow{4}{*}{ Regulative Factors } & Government policies & \multirow{4}{*}{ Scott (2001), Nawaz (2009). } \\
\hline & Institutional policies & \\
\hline & Bank policies & \\
\hline & Tax policies & \\
\hline \multirow{3}{*}{ Normative Factors } & Social factors & \multirow{3}{*}{$\begin{array}{l}\text { Rahman, Hossain and Miah (2000), Islam and } \\
\text { Aktaruzzaman (2001), Islam and Aktaruddin } \\
\text { (2003), Nawaz (2009) }\end{array}$} \\
\hline & Availability of capital & \\
\hline & Market contacts & \\
\hline \multirow{4}{*}{ Cognitive Factors } & Risk assessment capacity & \multirow{4}{*}{$\begin{array}{l}\text { Islam and Aktaruzzaman (2001), Hossain anc } \\
\text { Rahman (1999) }\end{array}$} \\
\hline & Education and access to information & \\
\hline & Entrepreneurial training & \\
\hline & Business Knowledge & \\
\hline
\end{tabular}




\section{ResEARCH MethodS}

This study is based on both primary and secondary sources of information. To determine the sample size of the retail women entrepreneurs, published formula of University of Florida was used as a reference. This study used formula for taking sample data from population suggested by Yamane, (1967).

$$
\mathrm{n}=\frac{N}{1+N e^{2}}
$$

Where, $\mathrm{n}=$ Sample Size, $\mathrm{N}=$ Population, $\mathrm{e}=$ Level of Precision, in calculating number of sample the following assumptions were made to determine, $n=218$, if Population size is more than 100000; Level of precision is $7 \%$.

\section{a) Statistical Tools Used}

Both descriptive and inferential statistics were used to analyze the data. Inferential statistics like Confirmatory Factor Analysis (CFA) and Structural Equation Modeling (SEM) were used to confirm the respective factors. It also identified the critical influential factors which are related to develop of women entrepreneurship in retail business of Bangladesh.

b) Questionnaire Design and Test of Reliability

We have selected 218 respondents from retail business in Bangladesh. A structured questionnaire with
11 items was used to collect the data. This structured questionnaire with the 5-points scale was developed for the items related to critical factors for the development of women entrepreneurship in retail business of Bangladesh. Two demographic variables, namely, age, and education level were taken to ensure the variability of different variables.

\section{c) Data Collection}

The sample respondents were selected by using the convenience sampling method. After collecting 234 data, incomplete, biased, and or abnormally answered data were discarded through scrutinizing process and finally 218 data were used in the analysis. The reliability of 11 items in the questionnaire has been tested by using SPSS software.

\section{d) Participants and Procedures}

Out of 218 respondents, $71 \%$ are from $28-35$ years, $23 \%$ are from $36-45$ years and $6 \%$ are from $45 \mathrm{yrs}$ and above age group. With regards to education, 5\% completed primary, $9 \%$ secondary, $18 \%$ higher secondary, $19 \%$ honors and 49\% completed Master's education (Table 2).

Table 2: Descriptive Statistics

\begin{tabular}{|c|c|c|}
\hline Particulars & Frequency & Percent \\
\hline \multicolumn{3}{|c|}{ Age } \\
\hline 28-35 years & 155 & 71.1 \\
\hline 36-45 years & 50 & 22.9 \\
\hline 45 years and above & 13 & 6.0 \\
\hline \multicolumn{2}{|c|}{} \\
\hline Primary & Education \\
\hline Secondary & 10 & 5 \\
\hline Higher Secondary & 20 & 9 \\
\hline Honors & 40 & 18 \\
\hline Masters & 42 & 19 \\
\hline
\end{tabular}

e) Normality of Data

According to Tabachnick and Fidell (2001), the value of Skewness and kurtosis statistic lies between -4 to +4 that is deemed to be acceptable. Table 3 shows that all the data met the acceptable range indicating the normal distribution of data.

Table 3: Normality of the Information

\begin{tabular}{|c|c|c|c|}
\hline \multicolumn{4}{|c|}{ Descriptive Statistics } \\
\hline & $\mathrm{N}$ & Skewness & Kurtosis \\
\hline RF1 & 218 & .278 & -.589 \\
\hline RF2 & 218 & .106 & -.749 \\
\hline RF3 & 218 & .385 & -.277 \\
\hline RF4 & 218 & -.174 & -.664 \\
\hline NF1 & 218 & -.066 & -.816 \\
\hline NF2 & 218 & -.109 & -.834 \\
\hline NF3 & 218 & -.014 & -.646 \\
\hline
\end{tabular}




\begin{tabular}{|c|c|c|c|}
\hline CF1 & 218 & .187 & -.963 \\
\hline CF2 & 218 & -.459 & -.714 \\
\hline CF3 & 218 & .335 & -.551 \\
\hline CF4 & 218 & .276 & -.905 \\
\hline
\end{tabular}

f) Test of Reliability and Validity

To analyze the reliability of the data, this study used the Cronbach's alpha, composite reliability, average variance extracted from the data are shown in Table -4 which is at the acceptable limit as per Nunnally and Berstein (1994), Hair et al. 1998, Fornell \& Larcker, (1981); Henseler, Ringle, \& Sinkovics, (2009) respectively.
For checking the discriminant validity, we followed Fornell Larcker's (1981) criterion that compares the AVE value with corresponding correlation values with other variables. The square-root value of AVE needs to be greater than the corresponding correlation values with other variables (Hair et al., 2014). The Reliability and Discriminant Validity of the factors is shown in Table 4.

Table 4: Reliability and Discriminant Validity

\begin{tabular}{|c|c|c|c|c|c|c|}
\hline & CR & AVE & Cronbach's alpha & 1 & 2 & 3 \\
\hline 1. Normative Factors & 0.877 & 0.708 & 0.868 & 0.841 & & \\
\hline 2. Regulative Factors & 0.884 & 0.658 & 0.883 & 0.804 & 0.811 & \\
\hline 3. Cognitive Factors & 0.834 & 0.557 & 0.832 & 0.446 & 0.486 & 0.747 \\
\hline
\end{tabular}

Note: AVE>0.50 (Fornell \& Larcker, 1981); Henseler, Ringle, \& Sinkovics, 2009), Composite

Reliability $>0.70$ (Hair et al. 1998), Cronbach's alpha $>=0.60$, (Nunnally and Berstein (1994)).

g) The Coefficient of Determination

The analysis shows that the $R$ square value of the model is 0.406 . That means all three independent factors like normative factors, regulative factors; cognitive factors explained $40.6 \%$ of the variance in the overall factors of the women retail business entrepreneurs in Bangladesh.

\section{Results And Discussions}

In this section, results of Confirmatory Factor Analysis, and the results of Structural Equation Modeling are reported.

Results of Measurement Model

a) Results of Confirmatory Factor Analysis (CFA)

CFA was utilized to confirm the unidimensionality of measurement that resulted from the EFA. The relative chi-square for this model was 1.395 that was smaller than the three recommended by Marsh and Hocevar (1985). Other fit indexes also showed a good fit for the measurement model. The GFI is .954 which was greater than the recommended value of 0.90 (Joreskog \& Sorbom (1984). Moreover, the adjusted goodness of fit index (AGFI) is .925, which was greater than the 0.90 recommended by Anderson and Gerbing (1988). Furthermore, the non-incremental fit index, such as the comparative fit index (CFI) is .989 that was exceeding the recommended cut- off level of 0.90 (Bentler, 1990). Finally, the root means square error of approximation (RMSEA) was 0.043 , which also was greater than the suggested a good fit to the data (Browne \& Cudeck, 1993). The summary result is shown in Table 6. The fit indices showed a good model fit to the data. The other model fit indices were SRMR $=0.0442$, and $\mathrm{RMR}=0.036$ (Table 5 \& Figure 1).

Table 5: Model Fit Indices and their Acceptable Thresholds

\begin{tabular}{|c|c|c|c|}
\hline Goodness of Fit Indices & Value & Level of acceptance & Reference \\
\hline Chi-square/df & 1.395 & $<5.0$ & Marsh and Hocevar (1985) \\
\hline CFI & .989 & $>0.90$ & Bentler (1990) \\
\hline RMR & .036 & $<0.08$ & Hu \& Bentler (1998) \\
\hline GFI & .954 & $>0.90$ & Joreskog \& Sorbom (1993) \\
\hline AGFI & .925 & $>0.85$ & Anderson and Gerbig (1984) \\
\hline RMSEA & .043 & $<0.08$ & Browne \& Cudeck (1993) \\
\hline SRMR & .0442 & $<0.05$ & Hu and Bentler (1999) \\
\hline
\end{tabular}

In sum, the measurement model exhibited a fairly good fit for the data collected. The measurement model was further assessed for construct reliability and validity. Construct reliability can be interpreted as the resultant coefficient that is similar to that of Cronbach's alpha, except that it also takes into account the actual 
factor loadings rather than assuming each item to be equally weighted in the composite load determination. The construct reliability for all factors is above 0.70 in the measurement model exceeded 0.70, which identified as an acceptable threshold (Hair et al. 1998).

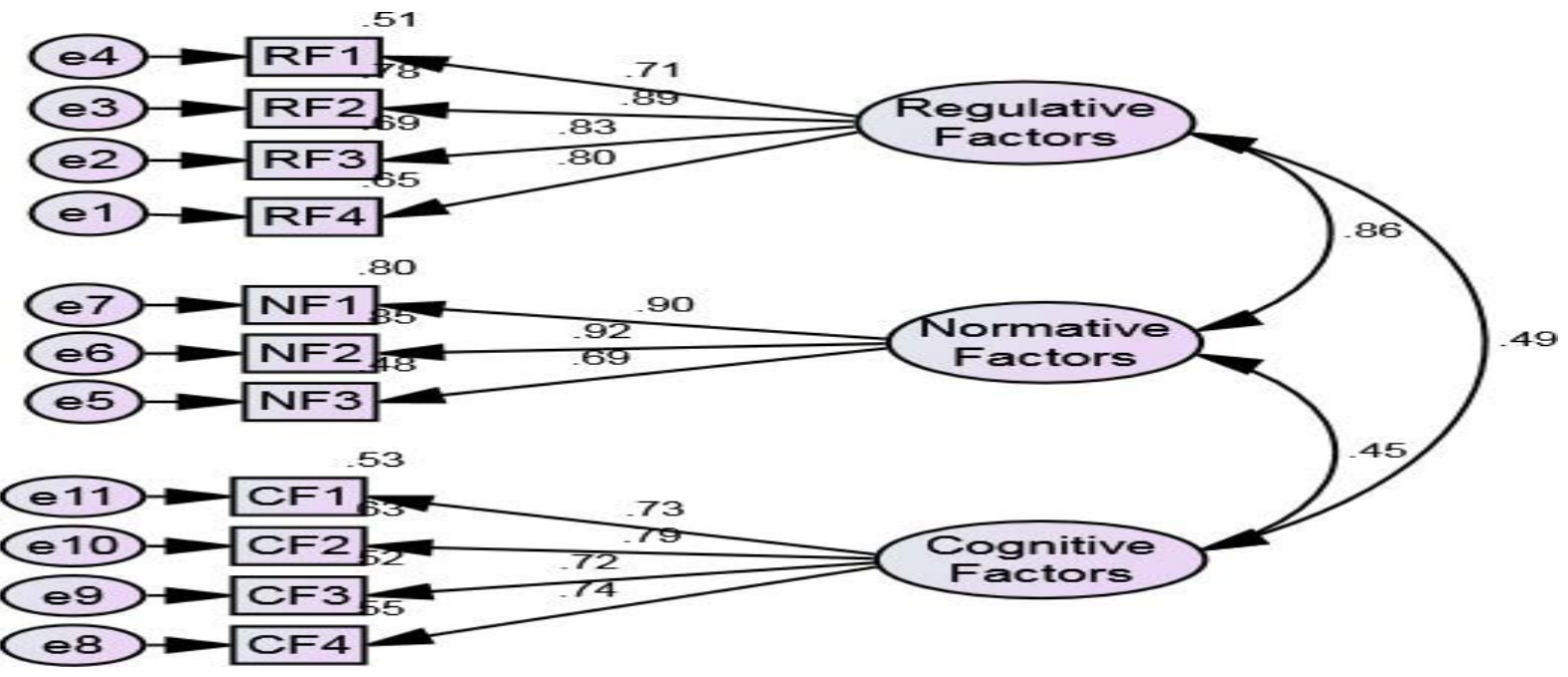

Figure 2: Confirmatory Factor Analysis of the Constructs

b) Results of Structural Model

A multivariate analysis technique like covariance-based structural equation modeling was used to identify the significant relationship between overall factors concerning women retail business entrepreneurship development and the factors identified through different factors like regulative factors, normative factors, and cognitive factors.

Table 6 lists the structural parameter estimates and the hypothesis testing results. This study examines the impact of regulative factors, normative factors, and cognitive factors to develop of women entrepreneurship in retail business of Bangladesh. The Path diagram (Figure 2$)$ revealed that only regulative factors $(=0.933$, $\mathrm{p}=.000$ ) positively influence the development of women entrepreneurs in retail business of Bangladesh. But normative factors $(=-0.283, p=.152)$ and cognitive factors $(=0.039, p=0.629)$ are not significantly related to the development of women entrepreneurs in retail business of Bangladesh. Hence, the results showed the support for $\mathrm{H} 1$ but not $\mathrm{H} 2$, and $\mathrm{H} 3$.

Table 6: Results of Structural Relationships

\begin{tabular}{|c|c|c|c|c|c|}
\hline Factors & Estimate & S.E. & C.R. & P & Comment \\
\hline Regulative Factor $\rightarrow$ Overall & .933 & .188 & 4.965 & 0.000 & Significant \\
\hline Normative Factor $\rightarrow$ Overall & -.283 & .198 & -1.432 & .152 & Not Significant \\
\hline Cognitive Factor $\rightarrow$ Overall & .039 & .080 & .483 & .629 & Not Significant \\
\hline $\mathrm{R}^{2}$ value & \multicolumn{5}{|c|}{.406} \\
\hline
\end{tabular}

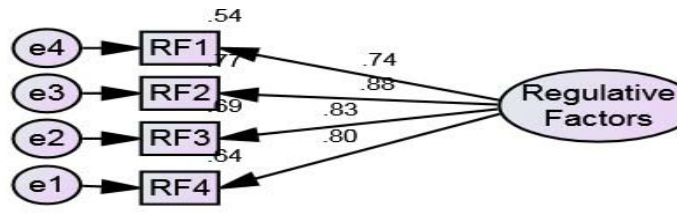

80

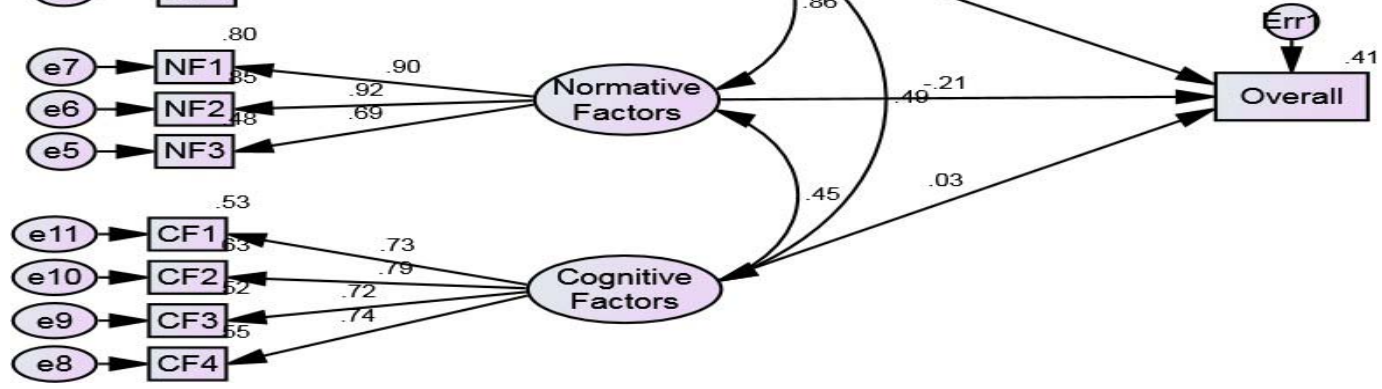

Figure 2: Path Model 


\section{Conclusions and Recommendations}

This study identified critical factors for the development of women retail business entrepreneurs of Bangladesh. CFA shows that all the three factors like regulatory factors, normative factors and cognitive factors are important factors concerning the development of women entrepreneurs in Bangladesh. Covariance-based structural equation modeling was used to identify the significant relationships between the overall factors of women retail business entrepreneurs and the factors identified through research like normative factors, regulative factors and cognitive factors. Results show that the regulative factors are the most important factors for the development of women retail business entrepreneurs in Bangladesh. The reason can be attributed by the overall business environment of the country which is beyond the control of the women entrepreneurs. Results also show that normative and cognitive factors are not significantly related to the overall development of women retail business entrepreneurs in Bangladesh. The reason can be attributed by the changing social culture of Bangladesh and the increase of women entrepreneurs in business. If the government, law enforcing agencies, and institutional supports are ensured, there will more women entrepreneurs in retail business sector of Bangladesh. Moreover, regulatory factors will have positive impact on the normative and cognitive factors concerning women entrepreneurs. Hence, government and other institutions should come forward to ensure the congenial environment of the business for the women entrepreneurs in Bangladesh. However, there is an ample scope to identify additional factors by taking more samples in consideration by further studies in future.

\section{References Références Referencias}

1. Afroze, T., Alam, M. K., Akther, E., \& Jui, N. S. (2015). Women entrepreneurs in BangladeshChallenges and determining factors. Journal of Business and Technology (Dhaka), 9 (2), 27-41.

2. Aktaruddin, M. (1999). A Case study of some Successful and Unsuccessful Entrepreneurs in Bangladesh. Journal of Business Administration, 25 (1 \& 2), 89-126.

3. Akehurst, G., Simarro, E., \& Mas-Tur, A. (2012). Women entrepreneurship in small service firms: Motivations, barriers and performance. The Service Industries Journal, 32 (15), 2489-2505.

4. Anderson, J. C., \& Gerbing, D. W. (1988). Structural Equation Modeling in Practice: A Review and Recommended Two-Step Approach. Psychological Bulletin, 103(3), 411- 423 .

5. Bentler, P. M. (1990). Comparative fit indexes in structural models. Psychological bulletin, 107 (2), 238.
6. Browne, M. W., \& Cudeck, R. (1993). Alternative ways of assessing model fit. Sage focus editions, 154, 136-136.

7. Fornell, C., \& Larcker, D. F. (1981). Structural equation models with unobservable variables and measurement error: Algebra and statistics. Journal of marketing research, 382-388.

8. Gedion, O., Oyugi, D. M., \& Munyithya, E. W. (2015). Effects of Women Enterprise Fund Loan on Women Entrepreneurs a Survey of Small and Medium Enterprises in Eldoret Town, Kenya. International Journal of Business and Social Science, 6(12), 72- 84.

9. Habibullah, M. (1987). Entrepreneurship training and development. Chittagong: Chittagong University, Faculty of Commerce, Bureau of Business Research, 47-58.

10. Habibur Rahman, A. H. M. (1995). Bank Credit for Women Entrepreneurship Development in Bangladesh. Bank Parikrama, 20, 67.

11. Hair, J. F., Anderson, R. E., Tatham, R. L., \& Black, W. C. (1998). Multivariate data analysis. 1998. Upper Saddle River.

12. Hussain, D., \& Yaqub, M. (2010). MicroEntrepreneurs: motivations, success factors, and challenges.

13. Jabeen, F., Katsioloudes, M. I., \& Das, S. S. (2015). Is family the key? Exploring the motivation and success factors of female Emirati entrepreneurs. International Journal of Entrepreneurship and Small Business, 25 (4), 375-394.

14. Jahan, L. B., (2017). What are the Issues \& Challenges Faced by Women Entrepreneur in Bangladesh When Entering Entrepreneurship? European Journal of Business and Management, 9 (29), 53-63.

15. Joreskog, K. G., \& Sorbom, D. (1989). LISREL 7: A guide to the program and applications. Chicago: SPSS. Inc. i.

16. Marsh, H. W., \& Hocevar, D. (1985). Application of Confirmatory Factor Analysis to the Study of Selfconcept: First-and Higher Order Factor Models and Their Invariance Across Groups. Psychological Bulletin, 97(3), 562-582.

17. Mohamad-Azahari, A., \& Joni-Tamkin, B. (2013). Success factors of successful microcredit entrepreneurs: Empirical evidence from Malaysia. International Journal of Business and Social Science, 4 (5).

18. Kariv, D. (2013). Female entrepreneurship and the new venture creation: An international overview. Routledge.

19. Kader, R. A., Mohamad, M. R. B., \& Ibrahim, A. A. H. C. (2009). Success Factors for Small Rural Entrepreneurs under the One-District-One-Industry Programme in Malaysia. Contemporary Management Research, 5 (2), 147-162. 
20. Klapper, L. F., \& Parker, S. C. (2010). Gender and the business environment for new firm creation. The World Bank Research Observer, 26(2), 237-257.

21. Meyer, N., \& Mostert, C. (2016). Perceived Barriers and Success Factors of Female Entrepreneurs Enrolled in an Entrepreneurial Programme. International Journal of Social Sciences and Humanity Studies, 8(1), 48-66.

22. Henseler, J., Ringle, C. M., \& Sinkovics, R. R. (2009). The use of partial least squares path modeling in international marketing. Advances in international marketing, 20, 277- 319.

23. Nawaz, F. (2009). Critical factors of women entrepreneurship development in rural Bangladesh.

24. Nunnally, J. U. M. (1994). C., BERSTEIN, Ira H. Psycometric theory. New York: McGraw Hill.

25. Philip, M. (2011). Factors affecting business success of small \& medium enterprises (SMEs). Amity Global Business Review, 6(1), 118-136.

26. Richardson, P., Howarth, R., \& Finnegan, G. (2004). The challenges of growing small businesses: Insights from women entrepreneurs in Africa. Geneva: International Labour Office.

27. Rahman, M. (2010). Barriers of women entrepreneurs in Bangladesh (Doctoral dissertation, BRAC University).

28. Rahmatullah, M., \& Zaman, F. (2014). Female Entrepreneurship in Bangladesh: Constraints, Motivation and Success. Bangladesh e-Journal of Sociology, 11(2), 65.

29. Singh, G., \& Belwal, R. (2008). Entrepreneurship and SMEs in Ethiopia: Evaluating the role, prospects and problems faced by women in this emergent sector. Gender in management: An international journal, 23(2), 120-136.

30. Saleh. Abu (1995). A Profile of the Women Entrepreneurship in Bangladesh. Journal of Business Studies (Dhaka University), 16(1), 159-170.

31. Tambunan, T. (2009). Women entrepreneurship in Asian developing countries: Their development and main constraints. Journal of Development and Agricultural Economics, 1(2), 027-040.

32. Watson, J. (2003). Failure Rates for Female-Controlled Businesses: Are They Any Different? Journal of small business management, $41(3), 262-277$.

33. Yamane, T. (1967). Elementary Sampling Theory. Englewood Cliffs, N.J.: Prentice-Hall. 